\title{
DIEZ AÑOS DE LA FACULTAD DE MEDICINA
}

Sergio A. Parra D. MD*

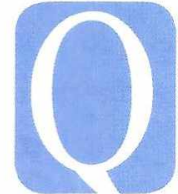

uiero a aprovechar la celebración de estos primeros diez años de nuestra facultad para compartir con ustedes algunos de los logros alcanzados en este corto y fructífero período. Logros que son el resultado del trabajo mancomunado de docentes, estudiantes, administrativos y directivos.

La gesta se inicia en diciembre de 1996 cuado la asamblea de la Sociedad de Cirugía de Bogotá autoriza a los doctores Darío Cadena y Luis Carlos Taborda, presidente y vicepresidente de esa época para realizar los tramites en pos de la obtención del registro del programa de medicina. A su vez el doctor Cadena comisionó a los doctores Eduardo Palacios, rector, Javier Francisco Barreto, vicerrector y Roberto Jaramillo, jefe de postgrados (todos ellos ilustres fundadores) para que desarrollaran esta labor y es así como en marzo de 1997 entregaron al ICFES la documentación necesaria para este fin. Se recibe visita de pares en septiembre de 1997 y el 16 de diciembre del mismo año obtenemos el registro del programa. La facultad inicia labores académicas con 43 alumnos el 5 de marzo de 1998 (algunos de los cuales nos acompañan hoy).

Empeñados desde el inicio en la excelencia académica se trabajó sin descanso para la obtención del registro calificado del programa bajo el liderazgo de nuestro querido y nunca olvidado maestro el doctor Alfonso Tribin Ferro. Registro que obtuvimos el 4 de agosto de 2003. En 2004 la asociación Colombiana de Facultades de Medicina nos acogió en su Consejo de Decanos y desde entonces nuestra facultad ha estado apoyada por la experiencia y oportunidades que esta asociación nos brinda (gracias Ascofame).

* Decano de la facultad de medicina de la Fundación Universitaria de Ciencias de la Salud. Bogotá. D.C. Colombia.

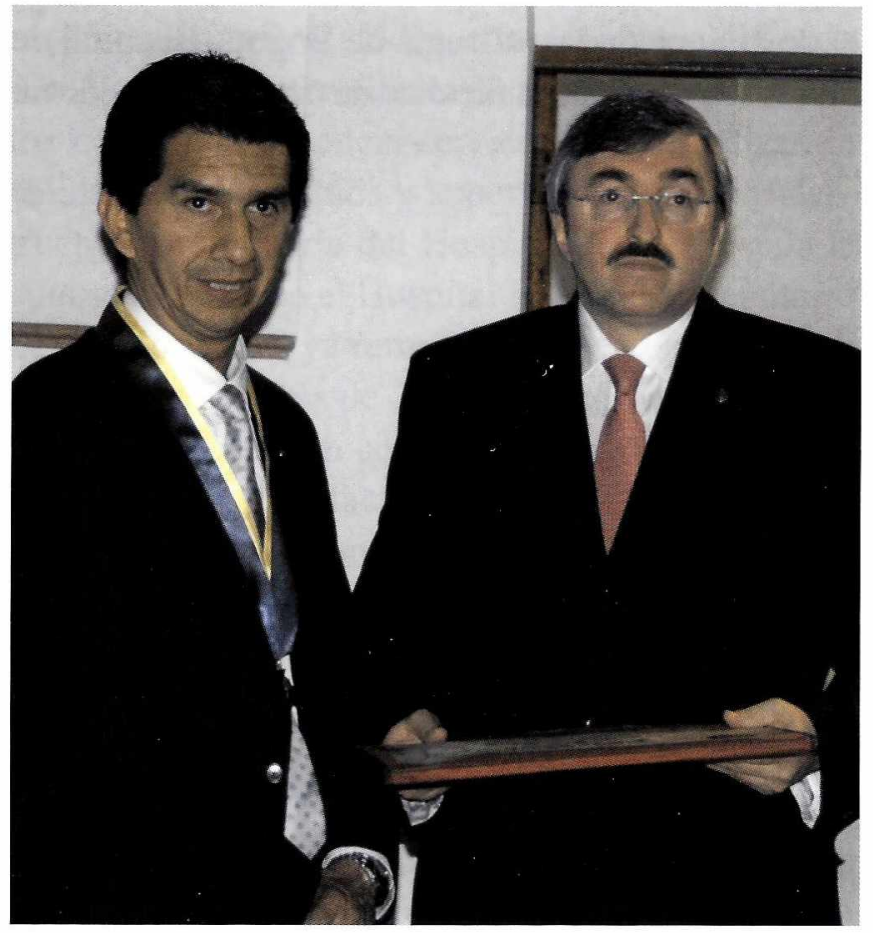

El Dr. Sergio A. Parra D. decano de la Facultad de Medicina de la Fundación Universitaria de Ciencias de la Salud, aparece acompañado por el Dr.Jorge Gómez, Presidente de la Sociedad de Cirugía de Bogotá, Hospital de San José, durante la celebración de los diez años de la facultad.

Hasta la fecha hemos entregado nueve promociones de excelentes médicos, como lo reconoce la comunidad nacional e internacional, ya unos de ellos con titulo de postgrado (obtenidos la mayoría también en nuestra facultad). Completamos los doce períodos académicos en el segundo semestre de 2003 y hasta la fecha la población estudiantil se ha incrementado en un $23 \%$. De la misma forma, con el nacimiento de la facultad los programas de postgrado han pasado de 22 en 1998 a 34 en la época actual, con el consecuente aumento de la población de residentes, haciéndonos más sólidos en nuestra fortaleza, las especializaciones medico quirúrgicas.

Quiero aquí hacer un reconocimiento especial a nuestro presidente del Consejo Superior y de la Sociedad 
de Cirugía el Dr. Jorge Gómez, que con su gestión desde el año 2000, le ha dado a la universidad y al programa una estructura académico administrativa de primera línea, que nos ha permitido llegar a donde estamos hoy. Es así como bajo su indeclinable y algunas veces soñador empeño, se logró la adquisición del antiguo Hospital Lorencita Villegas de Santos, hoy Hospital Infantil Universitario de San José, conformando así dos escenarios de práctica de altísima calidad para los programas de pregrado y postgrado de la FUCS. Sueño alcanzado con el apalancamiento financiero de una naciente pero promisoria facultad de medicina, que viene trabajando sobre tres pilares fundamentales, que son:

- Excelencia académica.

- Competitividad.

- Productividad.

Ya tenemos un camino trazado en la búsqueda de dicha excelencia y es el proceso que venimos desarrollando en pos de la acreditación de nuestro programa. Labor que la decanatura, el comité curricular y la oficina de calidad ha visto plasmado en el documento de autoevaluación entregado al CONACES el pasado 14 de marzo, quedando pendiente la visita de pares académicos. No se alcanza la excelencia, si no se demuestra calidad en forma voluntaria y esto es la acreditación. También obtuvimos el registro calificado de nuestros programas de postgrados. A la fecha solo tenemos pendiente la llegada de los registros de los programas de medicina de la actividad física y el deporte y medicina de urgencias (nuevos). Semanalmente sesiona nuestro comité curricular con el modelo de interlocución, buscando los mejores contextos pedagógicos para el óptimo rendimiento de nuestros alumnos.

En enero 8 de 2008 abrió sus puertas la oficina de egresados cuyo fin primordial es mantener el contacto con nuestros exalumnos a través de diferentes estrategias (bases de datos, carnetización, asociación, participación en cuerpos colegiados, autoevaluación, beneficios y canalización de empleos). Logramos mejorar nuestras tasas de permanencia estudiantil con nuevas estrategias didácticas, programas de tuto- res pares, tutores en casa y la aplicación efectiva del reglamento de becas. No se construye conocimiento si no se investiga, se fortaleció la investigación formativa en la aplicación de nuevas técnicas de estudio, búsqueda de información y medicina basada en la evidencia para las asignaturas clínicas.

En el 2007 se corrieron 36 trabajos de investigación aplicada que generaron 16 artículos científicos de publicación en revistas indexadas. Nos aprobaron además cinco trabajos en convocatoria interna.

Ser competitivos es ser mañana mejores que hoy. Posicionamos el Hospital Infantil como nuestro segundo escenario de práctica, hoy tenemos rotaciones de pregrado en pediatría, ginecoobstetricia, medicina interna y urgencias, así como rotaciones de residentes en 8 especialidades medico quirúrgicas. También sirve el área del hospital como base del primer y tercer semestres.

Gracias al proyecto de acompañamiento y tutoría a familias desplazadas con ASCOFAME y FUPAD se lograron captar a la fecha 980 familias con sus respectivas carpetas familiares, proyecto de vida y articulación a redes de apoyo (salud, empleo, comida, educación y vivienda). Proyecto que por primera vez nos saca del hospital para sentir la realidad de una problemática social, como son el desarraigo y la vulnerabilidad.

Seguimos desde nuestro saber médico desarrollando campañas de promoción y prevención en cada una de las disciplinas de nuestro programa. Es así como en alianza con el Instituto Nacional de Cancerología, la Secretaria de Salud de Bogotá y el Ministerio de la Protección Social, se culminó con éxito el tamizaje de 5.000 mujeres en Bosa, Usme y Ciudad Bolívar, bajo el proyecto de investigación "Evaluación de la citología cervical y la inspección visual en la rutina de los servicios de salud de Bogotá", proyecto que dejará al menos seis artículos de publicación con tiraje internacional.

Se ahondaron alianzas con IPS como el Hospital Centro Oriente, Hospital de Engativá, Hospital de 
Soacha, Instituto Nacional de Cancerología, Centro Policlínico del Olaya y Profamilia, buscando extender a estos escenarios nuestros servicios y programas. También fortalecemos las alianzas interinstitucionales en rotaciones específicas, en proyectos como la prevención de la violencia intrafamiliar con la Universidad Internacional de la Florida y la búsqueda de marcadores genéticos en preeclampsia con la Universidad Autónoma de Bucaramanga. Continuamos haciendo presencia con nuestros alumnos de internado en la Universidad de Miami, el Hospital de la Santa Creui San Pau de Barcelona y el Instituto Ruber de Madrid. Se han capacitado con el patrocinio de la FUCS más del 70\% de nuestro cuerpo docente en diferentes áreas del conocimiento. En los últimos dos años abrimos tres nuevos programas de postgrado y tenemos otros dos pendientes de registro. En la actualidad contamos con 15 diplomados de los cuales 4 se lanzaron en el último año y otros como los médicos quirúrgicos tienen tal demanda, que hay lista de espera hasta de un año.

La facultad ofrece cursos de capacitación en áreas de la salud a clientes tan diversos como la fuerza de la venta de los laboratorios farmacéuticos, profesores de secundaria y regentes de farmacia. Bajo la coordinación de la facultad de medicina se abrió el centro de investigaciones farmacológicas en humanos en febrero de
2007. Se llevan a cabo doce trabajos, con el patrocinio de importantes empresas multinacionales.

La facultad dio vida al proyecto de "medicina laboral" con objetivos concretos como son la consecución de las licencias para prestar servicios de medicina del trabajo en nuestros hospitales y montar líneas de investigación y programas de formación en el área para la Fundación. No somos ajenos a la evolución de las telecomunicaciones, es así como entramos en el espacio de la telemedicina, con una propuesta concreta, en interpretación de teleimágenes para radiología, cardiología y citohistotecnología. A través de microondas y el proyecto de desplazados, realizamos la primera prueba piloto en lectura de citologías a distancia. Ahora tenemos las cotizaciones para los equipos de recepción, emisión e interconexión los cuales pensamos adquirir pronto. Se adecuó el programa de medicina familiar para especializar recurso humano de EPS's en sus sitios de trabajo, con sus propios pacientes; modelos que ya desarrollamos con éxito en Salud Total y Colmédica.

Queridos compañeros y amigos aquí estamos ahora, y con la ayuda de Dios sabremos enfrentar los retos de los próximos diez años.

Gracias.

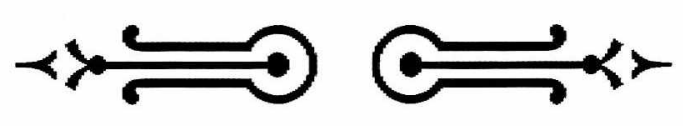

